\begin{tabular}{|l|l|}
\hline $\begin{array}{l}\text { Postprint } \\
\text { Version }\end{array}$ & 1.0 \\
\hline Journal website & $\underline{\mathrm{http} / / / \mathrm{dx} . \text { doi.org/10.1016/j.pec.2009.10.010 }}$ \\
\hline Pubmed link & $\underline{\mathrm{http} / / / \mathrm{www} \text {.ncbi.nlm.nih.gov/pubmed/20005066 }}$ \\
\hline DOI & $10.1016 / \mathrm{j}$. pec.2009.10.010 \\
\hline
\end{tabular}

This is a NIVEL certified Post Print, more info at http://www.nivel.eu

\title{
Emotional and informational patient cues: The impact of nurses' responses on recall
}

\author{
JESSE JANSEN ${ }^{A, B}$, JULIA C.M. VAN WEERT ${ }^{\mathrm{C}}$, JUDITH DE GROOT ${ }^{\mathrm{D}}$, SANDRA VAN DULMEN ${ }^{\mathrm{B}}$, THEA J. \\ HEEREN $^{\mathrm{E}}$ AND JOZIEN M. BENSING ${ }^{\mathrm{B}, \mathrm{F}}$ \\ ${ }^{a}$ Screening and Test Evaluation Program, Sydney School of Public Health, Centre for Medical Psychology \\ and Evidence-based Decision-making (CeMPED), University of Sydney, Australia \\ ${ }^{b}$ NIVEL (Netherlands Institute for Health Services Research), Utrecht, The Netherlands \\ ${ }^{\mathrm{c}}$ The Amsterdam School of Communication Research ASCoR, University of Amsterdam, Amsterdam, The \\ Netherlands \\ ${ }^{\mathrm{d}}$ Comprehensive Cancer Centre North East, Groningen, The Netherlands \\ e Symfora Group, Centers for Mental Health Care, Amersfoort, The Netherlands \\ ${ }^{f}$ Department of Psychology, Utrecht University, Utrecht, The Netherlands
}

\begin{abstract}
Objective: To investigate older cancer patients' informational and emotional cues, how nurses respond to these cues and the effect of cues and responses on patients' information recall.

Methods: 105 cancer patients (aged $\geq 65$ years) completed a recall questionnaire after an educational session preceding chemotherapy treatment. Recall was checked against the actual communication in videorecordings of the consultations. Patients' emotional and informational cues and subsequent responses by the nurse were rated using an adaptation of the Medical Interview Aural Rating Scale (MIARS).

Results: Patients gave more informational than emotional cues. The most frequent response to emotional cues was distancing followed by acknowledgement. Nurses gave appropriate information in response to the majority of informational cues. Patients' expression of emotional or informational cues did not influence recall; neither did nurses' responses to informational cues. Responses to emotional cues did affect recall. The more nurses responded by giving 'minimal' encouragements (e.g. 'Hmmm'), the more patients recalled, while distancing responses (e.g. switching focus) were associated with lower recall scores.

Conclusion: Responding to patients' emotions is likely to impact information recall.

Practice implications

These results highlight the importance of addressing patients' expressions of emotions in the context of patient education, as it enhances information recall.
\end{abstract}

\section{INTRODUCTION}

Having cancer is very distressing for most patients [1], [2] and [3]. Patients not only have to cope with the diagnosis of a life threatening illness, but also face invasive treatments and tests and have to make difficult decisions. Not surprisingly, most cancer patients report high needs for information and emotional support [4] and [5]. It is an important task for health providers to address the patient's emotions while concurrently 
giving information that the patient will understand and remember [6]. However, it is unclear how health providers' responses to patients' emotions influence cognitive outcomes of the consultation, such as recall.

Despite their high needs for information and support, cancer patients are often hesitant to clearly verbalize these needs and more likely to disclose their concerns indirectly, by what is often labelled 'cues' [1], [7] and [8]. Cues are important to address as they may provide insight into the perspective of the patient and his or her feelings. According to a recent literature review [8], responses such as clarifying the cue, empathy, showing agreement (e.g. 'Go on'), acknowledgement of feelings, are generally considered adequate. On the other hand, postponing, interrupting and avoiding cues or discouraging further disclosure are deemed less adequate responses.

Patients are an expert of their own physical and psychological states [9] and adequate responses to cues may encourage patients to disclose their perspectives on illness and treatment [10] and [11]. This may in turn reduce the patients' feelings of distress, increase the chance that the patient's agenda is voiced and that the information in the consultation is attuned to their needs [10] and [12]. Increased personal relevance of information has been associated with increased information recall, and responses to patients' cues might thus influence recall [13] and [14]. How distress and emotions influence patients' recall is more difficult to predict as the psychological literature shows that the relationship between emotions and memory is complex and context dependent [15], [16], [17], [18], [19] and [20]. On one hand, strong emotions and distress may hamper information processing and recall. On the other hand, emotions may help people to integrate information more effectively and may motivate people to process information more or less extensively.

Responding to cues may be even more important when communicating with older cancer patients, as they are less likely to express themselves [1], [21], [22] and [23]. Also, as people get older, they increasingly focus on information that is emotionally meaningful to them [24]. When put into an emotionally meaningful context, it may be easier for older people to process and therefore recall information [25] and [26]. Too much focus on emotions may, however, displace time for information giving and negatively influence recall [27], and patients may actually get more distressed [28].

Nurses play an important role in providing cancer patients with information about their disease and treatment. In this paper we specifically focus on education about chemotherapy treatment [29] and [30]. To optimally prepare patients for their treatment, information giving as well as responding to patients' emotional needs are major tasks for the nurse. Patients and professionals have reported that the emotional dimension of nursing communication may especially require improvement [31] and [32]. The purpose of this study was twofold:

1. To describe nurses' cue responding behaviour in educational sessions with older cancer patients in preparation for chemotherapy treatment.

2. To explore the effect of patients' emotional and informational cues and nurses' responses on patients' recall of information.

We used sequence analysis rather than the traditional descriptive analysis to allow for a better understanding of what response followed a cue. We expect improved patient recall of information when nurses adequately respond to cues. More specifically, we expect that responses to emotional cues that facilitate patients to express their worries will increase recall, whereas inhibiting disclosure will reduce recall. For informational cues, we expect that giving appropriate information and exploring cues will improve recall, whereas distancing responses and inappropriate information will reduce recall.

\section{METHODS}

\subsection{Participants}

Participants were recruited from consecutive new patients in 10 Dutch hospitals between February 2005 and April 2008. The Medical Ethical Committee of the University Medical Centre Utrecht, the Netherlands, granted permission for the study supplemented by local feasibility statements from all participating hospitals. To be eligible for the study, patients had to meet the following inclusion criteria: (a) aged 65 years or older, (b) receiving chemotherapy for the first time or for the first time in 5 years, (c) not participating in a Phase III clinical trial, (d) sufficient command of the Dutch language, and (e) no history of cognitive deficiencies according to the medical file.

This study was part of a larger study investigating the effects of a communication skills training for oncology nurses on patient outcomes. After a pre-test, hospitals that participated in the study were 
randomized to receive the training in which nurses practised addressing the emotional and informational needs of patients. In relation to the purpose of the current study, patients who were educated by a nurse who had received the training were excluded $(n=44)$ as it may have confounded the results.

\subsection{Procedure}

Eligible patients were sent a letter before the consultation to inform them of the study's purpose and requirements. Prior to the consultation, written informed consent was obtained from both patient and nurse, a researcher then started the video recording and left the room. The camera was positioned to show the nurse's full face, patients were seen from behind or the side. Immediately after the consultation, patients were asked to complete a questionnaire. A researcher was available to read the questions aloud to the patients, if necessary.

\subsection{Measures}

\subsubsection{Video observations of cues and responses}

A review of the literature [27] identified an observation instrument that best suited our aims, the Medical Interview Aural Rating Scale (MIARS) [33] and [34]. The MIARS is specifically developed for oncology settings and provides the number of emotional cues expressed by a patient and nurses' responses to each cue. As it does not cover informational cues, these were added to the instrument (see below). This instrument has been previously used to study cue responding behaviours of oncology nurses [11] and [33]. We used 'turns' as the unit of observation, meaning what the patient, companion or nurse says before the other takes over. A turn can therefore consist of several smaller elements or 'utterances'. Non-verbal factors (e.g. tone of voice, body posture) can influence the meaning of spoken language and help in identifying cues and categorizing responses. Consultations were coded directly from the videotapes so that these nonverbal aspects could be taken into account. The coding system was integrated in specialized software (The Observer [35]) and time and sequence indicators were automatically added during the coding procedure, resulting in sequential data.

\subsubsection{Emotional cues and responses}

Emotional cues were classified at three levels according to their level of intensity, i.e. hints-, mention- and clear expression of worry or concern. As cues are infrequent events, we collapsed these levels together to increase the power of the analyses [8]. The MIARS system distinguishes among three types of responses to emotional cues; exploration (eliciting, clarification, or educated guess), acknowledgment (empathic statement, reflection, or checking) and moving away or distancing (blocking further disclosure, switching focus, giving premature reassurance or inappropriate advice). Previous studies have shown that silence and minimal prompts like 'Mmmmh', 'Ah', 'Right' encourage further disclosure [28]. We therefore, added a category 'minimal encouragement' to the original instrument. This category is similar to 'back-channel' responses in the RIAS coding system [36], but our category includes silence. Only responses that immediately followed the patient cue were coded (i.e. in the first turn after the cue).

\subsubsection{Informational cues and responses}

Informational cues were defined as verbal information-seeking utterances, including direct questions (e.g., 'Will I lose my hair?') and indirect statements (e.g., 'So it seems like you do not think I will lose my hair?'). Responses to informational cues were coded as distancing and exploration responses, giving appropriate information and giving incomplete or inappropriate information. In line with Butow et al. [1], responses to informational cues were coded as appropriate if they covered material of the same content as the cue and provided complete coverage of the issues raised by the patient.

\subsubsection{Coding reliability cues and responses}

Previous studies have reported good interrater reliability of the MIARS [11] and [33]. In the current study, all tapes were rated by one of three raters. Raters practised coding until uncertainties and questions were satisfactorily resolved. In addition, all raters rated the same randomly selected sample of 20 consultations to calculate interrater reliability. Following Heaven et al. [33], reliability was tested using intra-class correlation coefficients (ICCs) using a two-way mixed effect model of consistency and single measure statistic. The ICC for coding informational cues was 0.76 and 0.58 for coding emotional cues. The ICC for 
the responses to informational cues ranged between 0.42 for distancing to 0.65 for giving appropriate information. Responses to emotional cues showed ICCs ranging from 0.33 for distancing to 0.52 for acknowledgement. Values between 0.21 and 0.40 can be considered fair, values between 0.41 and 0.60 moderate and values $>0.61$ good [37]. We considered responses to be reliable if the ICC was greater than 0.41 . We deemed this acceptable, because reliability for all responses was coded regardless of whether the coders agreed on the preceding cue. This implicates that the ICC of the responses can maximally be as high as the ICC of the preceding cue.

\subsubsection{Video observations of information discussed and recall}

The videotapes were analysed using an observation checklist developed for this study that is extensively described elsewhere [38]. The categories in the checklist covered two main domains: (a) information about treatment and related issues (e.g. number of treatments) and (b) recommendations on handling potential side effects (e.g. diet), resulting in complete content analysis of the consultation (i.e. total amount of information discussed). Interrater reliability (mean Cohen's Kappa) for the content analysis of the videotapes was 0.79 .

\subsubsection{Recall measurement}

Recall was measured using a structured questionnaire, the 'Netherlands Patient Information Recall Questionnaire (NPIRQ)' that was developed in conjunction with the observation checklist [31]. Items recalled in response to eleven open-ended questions (regarding recommendations about side effects) were compared with items mentioned by the nurse during the videotaped consultation. The number (absolute) and percentage (proportional) of facts recalled accurately were calculated. Interrater reliability (mean Cohen's Kappa) was 0.96.

\subsubsection{Background characteristics and medical details}

Socio-demographic variables were assessed by a self-reporting questionnaire. Nurses or physicians provided medical details for each patient enrolled in the study like diagnosis and treatment goal.

Current levels of generalized anxiety were measured with the shortened, Dutch version of the State-Trait Anxiety Inventory (STAI [40], [41] and [42]) Respondents indicated their level of agreement (from 'not at all' to 'very much so' on a 4-point Likert scale) to each of the items, with raw scores summed to produce a total score [10], [11], [12], [13], [14], [15], [16], [17], [18], [19], [20], [21], [22], [23], [24], [25], [26], [27], [28], [29], [30], [31], [32], [33], [34], [35], [36], [37], [38], [39] and [40] and higher values representing higher levels of anxiety. Cronbach's Alpha for the scale was 0.90 in this sample.

\subsubsection{Statistical analysis}

To determine differences between participants and non-responders, Chi-square $\left(\chi^{2}\right)$ tests and independent sample $t$-tests were used. We explored the influence of emotional and informational cues and the nurses' subsequent responses on the amount of information patients recalled. In the current data there is a nested structure captured by a three-level hierarchy. The measurements of patients (first level) are nested in nurses (second level) and hospitals (third level). We therefore used multilevel regression analysis with a random intercept to control for clustering. Throughout, effects were tested using two-sided Wald tests. The first regression analysis examined the effect of patients' emotional and informational cues on recall. In Model 1, the background characteristics (age, anxiety, gender and education) were introduced. In Model 2, emotional cues and informational cues were added. To control for consultation duration and amount of information discussed, these variables were introduced to the final model. Second, to establish the effect of the nurses' responses on recall, we conducted two separate regression analyses, one for responses to emotional cues (i.e. exploration, acknowledgement, 'minimal' encouragement and distancing) and one for responses to informational cues (exploration, appropriate information giving, inappropriate information giving and distancing). These analyses were the same as for the cues, but this time the responses were added in Model 2. To increase interpretability of the regression coefficients, all continuous variables were centred. The number of missing values was limited, as a researcher was present in the room and checked if all questions were answered. If items from multi-item scales were still missing, the sum score was transformed to the full-item equivalent if at least $75 \%$ of the items from the scale were completed. Analyses were performed with SPSS (version 16.0; SPSS Inc., Chicago, IL) and MLwiN 2.10 [43]. 


\section{RESULTS}

\subsection{Recruitment and sample}

Of 283 eligible patients, 182 patients (64\%) gave informed consent to videotape the consultation; 101 patients refused to participate: 60 felt it was too much, 19 did not want their consultation to be videotaped, 10 felt too sick or too tired, and 12 refused for other reasons or without giving a reason. Non-participating patients were older (mean age 73.7, $\mathrm{SD}=6.8$ ) than participating patients (mean age $72.2, \mathrm{SD}=4.8$; $p<0.05$ ). Participants and non-participants did not differ in gender. Forty-four participants were excluded because they belonged to the experimental group in the post-test. Of the resulting patients, 105 completed the recall questionnaire (82\%); their characteristics are given in Table 1.

\section{[TABLE 1]}

\subsection{Overview of cues and responses}

Patients gave more informational cues than emotional cues (Table 2). Eleven patients (10.5\%) did not express any emotional cues, one no informational cues $(1.0 \%)$ and one patient $(1.0 \%)$ did not express any cues at all. We looked at the median and average number of cues expressed in all videotaped consultations, including those in which no cues were given. Patients gave a median number of 4 and mean number of 6.4 emotional cues per consultation ( $\mathrm{SD}=6.2$; range $0-27$ ) whereas they expressed a median number of 11 and mean number of 13.9 informational cues per consultation $(\mathrm{SD}=10.6$; range $0-69$ ).

\section{[TABLE 2.]}

The most common response to emotional cues was distancing (35.8\%), followed by acknowledgement $(29.5 \%)$. Nurses responded to the majority of the informational cues $(65.7 \%)$ by giving appropriate information.

\subsection{Amount of information discussed and recall}

On average, nurses discussed 80.8 items in the consultation, of which 36.6 items were recommendations about side effects (Table 2). Patients remembered a mean number of 7.2 recommendations $(21.9 \%)$.

\subsection{Impact of cues and responses on recall}

Patient's emotional and informational cues did not influence their recall. However, the way nurses responded to emotional cues influenced patient recall in two ways; distancing responses negatively influenced recall $(B=-0.81, p=0.02)$ whereas there was a marginally significant positive effect of 'minimal' encouragements $(B=1.05, p=0.06)$ on recall (Table 3$)$. This suggests that the more nurses responded to emotional cues by providing 'minimal' encouragements (e.g. 'Hmmm'), the more the patient remembered. In contrast, when nurses distanced themselves from emotional cues, e.g. by ignoring them or switching the topic, patients remembered less. These effects were similar when using absolute rather than proportion recall. Furthermore, patients recalled less when they were male (e.g. model with responses to emotional cues; $B=6.11, p=0.01$ ), and when less educated (model with responses to emotional cues; $B=5.33, p=0.02)$. Finally, when more information was presented in the consultation patients remembered proportionally less (model with responses to emotional cues; $B=-0.16, p=0.02$ ). Nurses' responses to informational cues were not associated with recall.

\section{[TABLE 3.]}

\section{DISCUSSION AND CONCLUSION}

\subsection{Discussion}

\subsubsection{The impact of nurses' responses to emotional cues on recall}

In this study we used sequence analysis of cancer patients' cues and nurses' responses to look at their effects on patients' recall. Sequence analysis is relatively new in communication research and may give a more precise picture of the complex interactions between patients and clinicians than more traditional correlational methods [8], [11], [28] and [44]. 
Our main finding is that nurses' responses to emotional cues influenced patients' recall. The more 'minimal' encouragements nurses gave, the more information patients recalled, while distancing responses resulted in lower recall scores. These effects were similar for proportional and absolute recall. 'Minimal' encouragement responses included back-channel responses (e.g. 'Yes...', 'Hmmm', 'Right') and silence. It is important to note that if non-verbal aspects of the response (e.g. tone of voice) signalled that the nurse did not pick up the cue but rather responded in an automated and uninterested manner, we coded the response as distancing instead. Previous studies have shown that health care providers often give 'minimal' encouragements after patients exhibit cues [28], [45] and [46]. 'Minimal' encouragements are short but unobtrusive, do not interrupt the conversation flow and show interest. This may encourage patients to further express their concerns thereby creating a caring or positive context for the consultation [28]. Distancing responses are likely to achieve the exact opposite; they will shut down the patient's disclosure of further concerns and accounts of their 'life world' [47] and increase their distress. It is, however, important to note that the effect of the 'minimal' encouragement responses was merely a statistical trend $(p=.06)$ and this finding should be replicated in a larger study.

The current findings support a recent communication model by Neumann and colleagues [12]. According to this model, socio-emotional communication may improve patient outcomes via an affective-oriented path and cognitive/action-oriented path. Firstly, it helps patients feel understood and supported (affectiveoriented). Secondly, it will improve the informative aspects of the consultation by facilitating patients to reveal their concerns and facilitate the health providers' understanding of the patient's medical and psychological situation. As a result, the health provider is better able to attune information to the patient's needs (cognitive/action-oriented). The affective-oriented path may result in better recall, because patients may be less anxious and more receptive to the information when they feel understood and supported [15]. The cognitive/action-oriented path may result in better recall, as personally relevant information increases the patient's motivation to process the information and improves the likelihood that it is stored in memory [13] and [14]. Neither patient anxiety nor the expression of emotional cues per se was associated with recall, rendering the first explanation less likely.

It is unclear why two other types of responses to emotional cues that are generally deemed adequate, i.e. acknowledgement and exploration [8], did not improve patient recall. Only $10 \%$ of the responses were explorations suggesting that lack of statistical power may explain the absence of an effect. This argument does not hold for acknowledgment responses, as these were more common than 'minimal' encouragements. As argued by Eide et al. [28], in cancer contexts, such as the current study, direct communication about fears and emotions may provoke distress and therefore be less beneficial for patient outcomes. Similarly, other findings suggest that both not enough and too much focus on emotions may hamper effective communication [48]. Our findings provide some evidence for such a curvilinear relation between emotional communication and outcomes of communication.

\subsubsection{Nurses' responses to informational cues}

We expected that if patients express informational cues and nurses give an appropriate response, they will be better able to direct the information flow, increasing their understanding and recall [7], [49] and [50]. It is therefore surprising that neither patients' informational cues nor nurses' responses influenced recall. Patients may give informational cues because they have high needs for information or because they do not understand information presented to them, which may influence recall differently. Alternatively, other aspects of participating behaviour may be more predictive of information recall than the number of informational cues expressed. For example, if patients clearly voice their agenda, it may be easier for nurses to attune information hence reducing the patients' need to raise issues themselves [51]. The vast majority of informational cues were responded to by giving appropriate information (see also [1]). As there was little variation in the type of responses, we may have failed to establish their effect on recall.

\subsubsection{Cue giving and responses by the nurse}

Differences in the conceptualisation and measurement of cues, consultation length, type of health professional and patient characteristics make it difficult to compare different studies on cue responding [8]. Bearing this in mind, patients in our study disclosed informational cues more often than emotional cues echoing previous findings [1]. Eleven patients $(11 \%)$ did not express any emotional cues, which is lower than the $23 \%$ and $68 \%$ reported in previous studies in oncology [1] and [52]. In our study, patients 
expressed an average of 6.4 emotional cues and 13.9 informational cues (including explicit questions) per consultation. In accordance with our results, an overview of the literature on patients' emotional cues and concerns report a mean frequency range of between one and seven emotional cues per consultation [8]. In a study by Butow et al. [1] patients expressed a mean of 1.3 emotional cues, 2.3 informational cues and 9 questions. This study involved consultations with oncologists rather than nurses and the consultations were much shorter (on average $19 \mathrm{~min}$ ) than in our study (on average $56 \mathrm{~min}$ ), which may explain the discrepancy.

Regarding the responses to patients' emotional cues, two studies are directly comparable to our study, because they also used MIARS and studied nursing consultations [11] and [33]. We found that nurses distanced themselves from $36 \%$ of the emotional cues, acknowledged $30 \%$, gave 'minimal' encouragements to $25 \%$, and explored $10 \%$ of the cues. We added the category 'minimal' encouragement to the original MIARS protocol. When these responses are excluded, our results (49\% distancing, 38\% acknowledged 13\% explored), are comparable with Heaven et al. [33], who report 50\% distancing, 29\% acknowledged and $12 \%$ explored. However, these results are somewhat dissimilar from the study by Uitterhoeve et al. [11] reporting 50\% distancing but $17 \%$ acknowledgement and $32 \%$ exploration. Because the study by Uitterhoeve et al. [11] used standardized patients and the interviews in the study by Heaven et al. [33] explicitly aimed at identifying patients' concerns and emotions we cannot compare the number of cues expressed in these studies with our own results.

\subsubsection{Limitations of this study}

Some limitations of this study should be considered. Coding relatively rare events such as emotional cues and subsequent responses is challenging. The reliability of emotional and informational cues and the nurses' responses was moderate to good with one exception, the reliability of distancing responses to emotional cues proved insufficient. In the study by Uitterhoeve et al. [11], distancing responses were coded with high reliability. However, in their study, all nurses communicated with the same standardized patient (an actor), meaning that their consultations were more uniform than the real life consultations in our study and therefore probably easier to code reliably. Furthermore, a study by Zandbelt et al. [53] on patientcentred communication showed that the reliability of the facilitating dimension of the coding instrument that they developed was good to excellent, whereas the interrater reliability of the inhibiting dimension was only fair. Perhaps, inhibiting behaviours such as distancing responses to emotional cues are more difficult to judge, and further refinement of the coding criteria or additional training may be needed.

This study was limited to consultations with older cancer patients and should therefore be replicated in consultations with patients of all ages. However, the results are important for this patient group, since recall is more problematic for older cancer patients [54] and [55] and the socio-emotional context of the consultation may assist them in processing and remembering the information presented [26] and [56]. Future studies are also needed to establish whether or not the effect of responses to emotional cues on recall is stronger for older than younger cancer patients. Our study focused on negative emotions. Studies suggest that whereas strong negative emotions result in attentional narrowing [18], positive emotions result in the opposite, they broaden the scope of attention [57] and [58] and may therefore improve recall. In the future it is worthwhile to include patients' expressions of positive emotions. Of course, not all cues necessarily need to be responded to or need to be responded to in the same way. Qualitative studies may help identity the appropriateness of responses to cues of different contents and intensities.

\subsection{Conclusion}

Patients are clearly responsive to how nurses address their emotions. Previous studies have shown that emotional dimensions of communication influence affective outcomes of consultations in cancer care [59] and [60]; this study adds that they also influence cognitive outcomes such as recall.

\subsection{Practice implications}

Health providers' communication training should include attending to patient's cues particularly emotional cues, as this has an effect on information recall and may influence adherence to treatment not only in cancer care but possibly also in other chronic diseases. 
Jansen, J., Weert, J.C.M. van, Groot, J. de, Dulmen, S. van, Heeren, T.J., Bensing, J.M. Emotional and informational patient cues: the impact of nurses' responses on recall. Patient Education and Counseling-202 79(2), 218-224

\section{ACKNOWLEDGEMENTS}

We thank the patients and nurses who participated in this study. Furthermore, we would like to thank Janneke Noordman, Jessika Ouwerkerk, and Marit Schotten for their help in data acquisition and Nienke van der Meulen and Frank Tol who participated in the coding of the videotaped encounters. We gratefully acknowledge the Dutch Cancer Society (grant number NIVEL 2003-2973) for funding this study. We confirm all patient/personal identifiers have been removed or disguised so the patients/persons described are not identifiable and cannot be identified trough the details of the story.

\section{REFERENCES}

[1] P.N. Butow, R.F. Brown, M.H.N. Tattersall and S.M. Dunn, Oncologists' reactions to cancer patients verbal cues, Psychooncology 11 (2002), pp. 47-58. )

[2] L. Fallowfield and V. Jenkins, Effective communication skills are the key to good cancer care, Eur J Cancer 35 (1999), pp. 1592-1597.

[3] P.B. Jacobsen and H.S. Jim, Psychosocial interventions for anxiety and depression in adult cancer patients: achievements and challenges, CA Cancer J Clin 58 (2008), pp. 214-230.

[4] T.F. Hack, L.F. Degner and P.A. Parker, The communication goals and needs of cancer patients: a review, Psychooncology 14 (2005), pp. 831-845 discussion 46-7.

[5] L.J. Rutten, N.K. Arora, A.D. Bakos, N. Aziz and J. Rowland, Information needs and sources of information among cancer patients: a systematic review of research (1980-2003), Patient Educ Couns 57 (2005), pp. 250-261.

[6] R.M. Epstein and R.L.J. Street, Patient-centered communication in cancer care: promoting healing and reducing suffering, National Cancer Institute (2007) NIH Publication No. 07-6225.

[7] A. Dimoska, M.H.N. Tattersall, P.N. Butow, H. Shepherd and P. Kinnersley, Can a "Prompt List" empower cancer patients to ask relevant questions?, Cancer 113 (2008), pp. 225-237.

[8] C. Zimmermann, L. Del Piccolo and A. Finset, Cues and concerns by patients in medical consultations: a literature review, Psychol Bull 133 (2007), pp. 438-463.

[9] C. De Valck, J.M. Bensing, R. Bruynooghe and V. Batenburg, Cure-oriented versus care-oriented attitudes in medicine, Patient Educ Couns 45 (2001), pp. 119-126.

[10] L.B. Mauksch, D.C. Dugdale, S. Dodson and R. Epstein, Relationship, communication, and efficiency in the medical encounter: creating a clinical model from a literature review, Arch Intern Med 168 (2008), pp. 1387-1395.

[11] R. Uitterhoeve, J. de Leeuw, J. Bensing, C. Heaven, G. Borm and P. Demulder et al., Cue-responding behaviours of oncology nurses in video-simulated interviews, J Adv Nurs 61 (2007), pp. 71-80.

[12] M. Neumann, M. Wirtz, E. Bollschweiler, S.W. Mercer, M. Warm and J. Wolf et al., Determinants and patient-reported long-term outcomes of physician empathy in oncology: a structural equation modelling approach, Patient Educ Couns 69 (2007), pp. 63-75.

[13] R.E. Petty, R. Goldman and J.T. Cacioppo, Personal involvement as a determinant of argument-based persuasion, J Pers Soc Psychol 41 (1981), pp. 847-855.

[14] B.K. Rimer and M.W. Kreuter, Advancing tailored health communication: a persuasion and message effects perspective, J Commun 56 (2006), pp. S184-S201.)

[15] M.J. Pickersgill and A. Owen, Mood-states, recall and subjective comprehensibility of medical information in nonpatient volunteers, Pers Indiv Differ 13 (1992), pp. 1299-1305.

[16] S.A. Christianson, Emotional stress and eyewitness memory: a critical review, Psychol Bull 112 (1992), pp. 284-309.

[17] Y. Hanoch and O. Vitouch, When less is more: information, emotional arousal and the ecological reframing of the Yerkes-Dodson law, Theory Psychol 14 (2004), pp. 427-452.

[18] J.A. Easterbrook, The effect of emotion on cue utilization and the organization of behavior, Psychol Rev 66 (1959), pp. 183-201.

[19] R.P.C. Kessels, Patients' memory for medical information, J R Soc Med 96 (2003), pp. 219-222.

[20] I. Wessel, P. van der Kooy and H. Merckelbach, Differential recall of central and peripheral details of emotional slides is not a stable phenomenon, Memory 8 (2000), pp. 95-109. )

[21] S. Eggly, L.A. Penner, M. Greene, F.W. Harper, J.C. Ruckdeschel and T.L. Albrecht, Information seeking during "bad news" oncology interactions: question asking by patients and their companions, Soc Sci Med 63 (2006), pp. 2974-2985.

[22] M.G. Greene and R.D. Adelman, Psychosocial factors in older patients' medical encounters, Res Aging 18 (1996), pp. 84-102. 
Jansen, J., Weert, J.C.M. van, Groot, J. de, Dulmen, S. van, Heeren, T.J., Bensing, J.M. Emotional and informational patient cues: the impact of nurses' responses on recall. Patient Education and Counseling 20 79(2), 218-224

[23] L.A. Siminoff, G.C. Graham and N.H. Gordon, Cancer communication patterns and the influence of patient characteristics: disparities in information-giving and affective behaviors, Patient Educ Couns 62 (2006), pp. 355-360.

[24] L.L. Carstensen, D.M. Isaacowitz and S.T. Charles, Taking time seriously-a theory of socioemotional selectivity, Am Psychol 54 (1999), pp. 165-181. Abstract |

[25] T.M. Hess, Memory and aging in context, Psychol Bull 131 (2005), pp. 383-406.

[26] Y. Hanoch, S. Wood and T. Rice, Bounded rationality, emotions and older adult decision making: not so fast and yet so frugal, Hum Dev 50 (2007), pp. 333-358.

[27] K. Rost and D. Roter, Predictors of recall of medication regimens and recommendations for life-style change in elderly patients, Gerontologist 27 (1987), pp. 510-515. View Record in Scopus | Cited By in Scopus (28)

[28] H. Eide, V. Quera, P. Graugaard and A. Finset, Physician-patient dialogue surrounding patients' expression of concern: applying sequence analysis to RIAS, Soc Sci Med 59 (2004), pp. 145-155.

[29] P. Schofield, M. Jefford, M. Carey, K. Thomson, M. Evans and C. Baravelli et al., Preparing patients for threatening medical treatments: effects of a chemotherapy educational DVD on anxiety, unmet needs, and self-efficacy, Support Care Cancer 16 (2008), pp. 37-45.

[30] R. Verity, T. Wiseman, E. Ream, E. Teasdale and A. Richardson, Exploring the work of nurses who administer chemotherapy, Eur J Oncol Nurs 12 (2008), pp. 244-252.

[31] R. Uitterhoeve, E. Duijnhouwer, B. Ambaum and T. van Achterberg, Turning toward the psychosocial domain of oncology nursing: a main problem analysis in the Netherlands, Cancer Nursing 26 (2003), pp. 18-27.

[32] W. Caris-Verhallen, L. Timmermans and S. van Dulmen, Observation of nurse-patient interaction in oncology: review of assessment instruments, Patient Educ Couns 54 (2004), pp. 307-320.

[33] C. Heaven, J. Clegg and P. Maguire, Transfer of communication skills training from workshop to workplace: the impact of clinical supervision, Patient Educ Couns 60 (2006), pp. 313-325.

[34] C. Heaven and C. Green, Medical interview aural rating scale (2001).

[35] L.P.J.J. Noldus, R.J.H. Trienes, A.H.M. Hendriksen, H. Jansen and R.G. Jansen, The Observer VideoPro: new software for the collection, management, and presentation of time-structured data from videotapes and digital media files, Behav Res Meth Instrum Comput 32 (2000), pp. 197-206.

[36] D.L. Roter, Patient participation in the patient-provider interaction: the effects of patient question asking on the quality of interaction, satisfaction and compliance, Health Educ Monogr 5 (1977), pp. 281315.

[37] D.G. Altman, Practical statistical methods for medical research, Chapman and Hall, London (1991).

[38] J. Jansen, J. van Weert, N. van der Meulen, S. van Dulmen, T. Heeren and J. Bensing, Recall in older cancer patients: measuring memory for medical information, Gerontologist 48 (2008), pp. 149-157.

[39] S.M. Dunn, P.N. Butow, M.H.N. Tattersall, Q.J. Jones, J.S. Sheldon and J.J. Taylor et al., General information tapes inhibit recall of the cancer consultation, J Clin Oncol 11 (1993), pp. 2279-2285.

[40] C.D. Spielberger, State-trait anxiety inventory (self-evaluation questionnaire), Consulting Psychologists Press, Palo Alto University, California (1983) Contract No.: Document Number.

[41] M.A. Stanley, D.M. Novy, S.L. Bourland, J.G. Beck and P.M. Averill, Assessing older adults with generalized anxiety: a replication and extension, Behav Res Ther 39 (2001), pp. 221-235.

[42] van der Ploeg HM, Defares PB, Spielberger CD. Handleiding bij de Zelfbeoordelings Vragenlijst (ZBV) [Manual of the Dutch version of the State Trait Anxiety Inventory]. Lisse: Swets and Zeitlinger; 1980.

[43] J. Rasbash, W. Browne, H. Goldstein, M. Yang, I. Plewis and M. Healy, A user's guide to MLwiN (2000).

[44] L. Del Piccolo, M.A. Mazzi, G. Dunn, M. Sandri and C. Zimmermann, Sequence analysis in multilevel models. A study on different sources of patient cues in medical consultations, Soc Sci Med 65 (2007), pp. 2357-2370.

[45] M. Rimondini, L. Del Piccolo, C. Goss, M. Mazzi, M. Paccaloni and C. Zimmermann, Communication skills in psychiatry residents-how do they handle patient concerns? An application of sequence analysis to interviews with simulated patients, Psychother Psychosom 75 (2006), pp. 161-169.

[46] Y.M. Kim, A. Kols, S. Prammawat and W. Rinehart, Sequence analysis: responsiveness of doctors to patient cues during family planning consultations in Mexico, Patient Educ Couns 58 (2005), pp. $114-117$.

[47] C.A. Barry, F.A. Stevenson, N. Britten, N. Barber and C.P. Bradley, Giving voice to the lifeworld. More humane, more effective medical care? A qualitative study of doctor-patient communication in general practice, Soc Sci Med 53 (2001), pp. 487-505.

[48] M. Schmid Mast, A. Kindlimann and W. Langewitz, Recipients' perspective on breaking bad news: how you put it really makes a difference, Patient Educ Couns 58 (2005), pp. 244-251. 
[49] N. van der Meulen, J. Jansen, S. van Dulmen, J. Bensing and J. van Weert, Interventions to improve recall of medical information in cancer patients: a systematic review of the literature, Psychooncology 17 (2008), pp. 857-868.

[50] J. Harrington, L.M. Noble and S.P. Newman, Improving patients' communication with doctors: a systematic review of intervention studies, Patient Educ Couns 52 (2004), pp. 7-16.

[51] L.M. Timmermans, R.W. van der Maazen, K.P. van Spaendonck, J.W. Leer and F.W. Kraaimaat, Enhancing patient participation by training radiation oncologists, Patient Educ Couns 63 (2006), pp. 5563.

[52] S. Ford and A. Hall, Communication behaviours of skilled and less skilled oncologists: a validation study of the Medical Interaction Process System (MIPS), Patient Educ Couns 54 (2004), pp. $275-282$.

[53] L.C. Zandbelt, E.M.A. Smets, F.J. Oort and H. de Haes, Coding patient-centred behaviour in the medical encounter, Soc Sci Med 61 (2005), pp. 661-671. )

[54] J. Jansen, P.N. Butow, J.C. van Weert, S. van Dulmen, R.J. Devine and T.J. Heeren et al., Does age really matter? Recall of information presented to newly referred patients with cancer, J Clin Oncol 26 (2008), pp. 5450-5457.

[55] S.C. Brown and D.C. Park, Theoretical models of cognitive aging and implications for translational research in medicine, Gerontologist 43 (2003), pp. 57-67 Spec No. 1.

[56] C.E. Lockenhoff and L.L. Carstensen, Socioemotional selectivity theory, aging, and health: the increasingly delicate balance between regulating emotions and making tough choices, J Pers 72 (2004), pp. 1395-1424.

[57] G. Rowe, J.B. Hirsh and A.K. Anderson, Positive affect increases the breadth of attentional selection, Proc Natl Acad Sci USA 104 (2007), pp. 383-388.

[58] B.L. Fredrickson, Positive emotions broaden the scope of attention and thought-action repertoires (2005).

[59] L.A. Fogarty, B.A. Curbow, J.R. Wingard, K. McDonnell and M.R. Somerfield, Can 40 seconds of compassion reduce patient anxiety?, J Clin Oncol 17 (1999), pp. 371-379.

[60] P.E. Schofield, P.N. Butow, J.F. Thompson, M.H.N. Tattersall, L.J. Beeney and S.M. Dunn, Psychological responses of patients receiving a diagnosis of cancer, Ann Oncol 14 (2003), pp. 48-56. 
Jansen, J., Weert, J.C.M. van, Groot, J. de, Dulmen, S. van, Heeren, T.J., Bensing, J.M. Emotional and informational patient cues: the impact of nurses' responses on recall. Patient Education and Counseling 202 79(2), 218-224

\section{TABLES}

Table 1

Patient characteristics $(n=105){ }^{\mathrm{a}}$.

\begin{tabular}{|c|c|c|c|}
\hline & $N$ & & $\%$ \\
\hline \multicolumn{4}{|l|}{ Gender } \\
\hline Female & 34 & & 32.4 \\
\hline Male & 71 & & 67.6 \\
\hline \multicolumn{4}{|l|}{ Age } \\
\hline Mean (range) & & $72.4(65.0-85.7)$ & \\
\hline SD & & 4.9 & \\
\hline$N$ & & 105 & \\
\hline \multicolumn{4}{|l|}{ Educational level } \\
\hline Low & 47 & & 44.8 \\
\hline Middle & 23 & & 21.9 \\
\hline High & 34 & & 32.4 \\
\hline \multicolumn{4}{|l|}{ Diagnosis } \\
\hline Digestive/gastrointestinal & 41 & & 39.0 \\
\hline Lung & 24 & & 22.9 \\
\hline Genitourinary & 14 & & 13.3 \\
\hline Breast & 9 & & 8.6 \\
\hline Haematologic/blood & 10 & & 9.5 \\
\hline Gynaecologic & 5 & & 4.8 \\
\hline Other & 1.0 & & 1.0 \\
\hline \multicolumn{4}{|l|}{ Treatment goal } \\
\hline Curative & 22 & & 21.0 \\
\hline Palliative & 62 & & 59.0 \\
\hline \multicolumn{4}{|l|}{ Time since diagnosis (months) } \\
\hline Median (range) & & $1.4(0.0-216.0)$ & \\
\hline$N$ & & 101 & \\
\hline \multicolumn{4}{|l|}{ State anxiety ${ }^{\mathbf{b}}$} \\
\hline Mean (range) & & $20.6(10-38)$ & \\
\hline SD & & 5.7 & \\
\hline$N$ & & 102 & \\
\hline \multicolumn{4}{|l|}{ Consultation duration } \\
\hline Mean (range) & & $55.9(15.4-93.5)$ & \\
\hline SD & & 14.3 & \\
\hline$N$ & & 105 & \\
\hline \multicolumn{4}{|c|}{ Amount of information presented } \\
\hline \multicolumn{4}{|l|}{ Information total } \\
\hline Mean (range) & & $80.8(32-127)$ & \\
\hline SD & & 20.6 & \\
\hline$N$ & & 105 & \\
\hline \multicolumn{4}{|l|}{ Information treatment } \\
\hline Mean (range) & & $44.2(18-64)$ & \\
\hline $\mathrm{SD}$ & & 10.2 & \\
\hline$N$ & & 105 & \\
\hline \multicolumn{4}{|l|}{ Recommendations side effects } \\
\hline Mean (range) & & $36.6(7-69)$ & \\
\hline SD & & 13.0 & \\
\hline$N$ & & 105 & \\
\hline \multicolumn{4}{|l|}{ Recall (absolute) } \\
\hline Mean (range) & & $7.2(0-17)$ & \\
\hline SD & & 3.8 & \\
\hline$N$ & & 105 & \\
\hline \multicolumn{4}{|l|}{ Recall (proportion) ${ }^{c}$} \\
\hline Mean (range) & & $21.9(0-72.7)$ & \\
\hline $\mathrm{SD}$ & & 11.8 & \\
\hline$N$ & & 105 & \\
\hline
\end{tabular}

a Numbers do not always add up to 105 or $100 \%$ due to missing values.

b Normal range: 10-40, higher scores indicate greater anxiety.

c Normal range: $0-100 \%$. 


\section{Table 2}

Total number of patient cues and the different types of responses by the nurse (adaptation of the MIARS). ${ }^{\mathrm{a}}$.

\begin{tabular}{lcl}
\hline Elements of the MIARS & $\begin{array}{l}\text { Frequencies } \\
n(\%)\end{array}$ & $\begin{array}{l}\text { Intra-class correlation } \\
\text { coefficients }(95 \% \mathrm{CI})\end{array}$ \\
\hline Patient cues & $667(68.6)$ & $0.58(0.32-0.78)$ \\
$\quad$ Emotional cues & $1457(31.4)$ & $0.76(0.57-0.89)$ \\
Informational cues & & \\
Nurses' responses & & \\
Emotional cues & $73(9.9)$ & $0.44(0.17-0.70)$ \\
$\quad$ Exploration & $160(29.5)$ & $0.52(0.25-0.75)$ \\
Acknowledgement & $275(35.8)$ & $0.33(0.10-0.62)^{\mathrm{b}}$ \\
$\quad$ Distancing & $156(24.7)$ & $0.51(0.25-0.75)$ \\
'Minimal' encouragement & & \\
Informational cues & $36(2.8)$ & $0.47(0.20-0.72)$ \\
Exploration & $942(65.7)$ & $0.65(0.41-0.83)$ \\
Appropriate information & $336(28.5)$ & $0.48(0.21-0.73)$ \\
Inappropriate information & $52(3.1)$ & $0.42(0.14-0.68)$ \\
Distancing & & \\
\hline
\end{tabular}

a $n=105$ for the cues, $n=93$ for the responses to the emotional cues ( 12 patients did not express emotional cues), and $n=103$ for the responses to the informational cues ( 2 patients did not express informational cues).

b Because the ICC for this response is $<0.41$, we consider it to be unreliably coded. 
Jansen, J., Weert, J.C.M. van, Groot, J. de, Dulmen, S. van, Heeren, T.J., Bensing, J.M. Emotional and informational patient cues: the impact of nurses' responses on recall. Patient Education and Counseling: 2010 79(2), 218-224

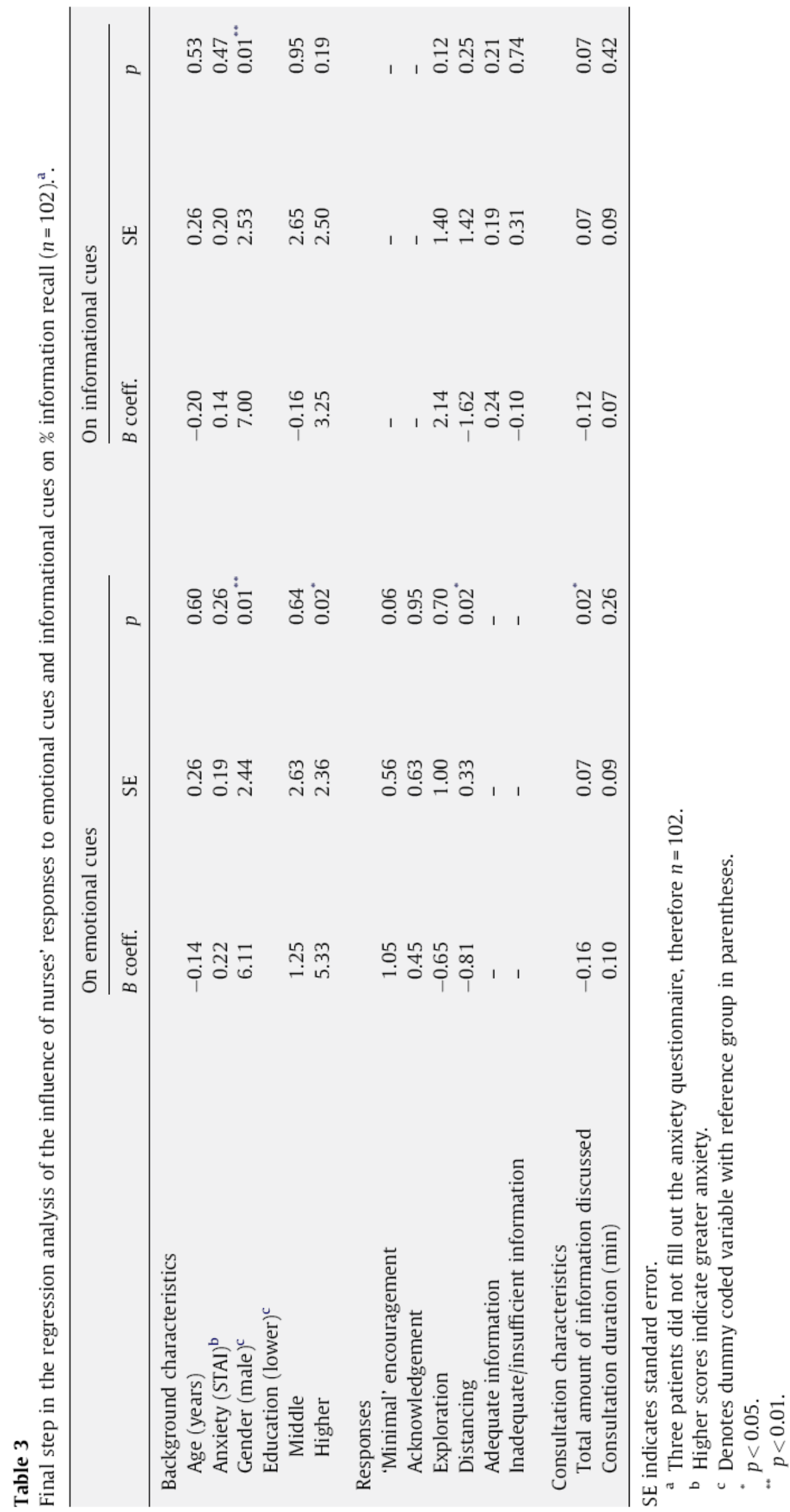

